\title{
Oxidation Behaviour of a Newly Developed Superalloy
}

\author{
I. V. S. Yashwanth ${ }^{1}$, I. Gurrappa ${ }^{2 *}$, H. Murakami ${ }^{3}$ \\ ${ }^{1}$ M. V. S. R. Engineering College, Nadargul, Hyderabad, India; ${ }^{2}$ Defence Metallurgical Research Laboratory, Kanchanbagh PO, Hy- \\ derabad, India; ${ }^{3}$ National Institute for Materials Science, Ibaraki, Japan. \\ Email: *igp1@rediffmail.com
}

Received July 19 ${ }^{\text {th }}$, 2011; revised August 31 $1^{\text {st }}$, 2011; accepted September $9^{\text {th }}$, 2011.

\begin{abstract}
The current paper explains the oxidation behaviour of a newly developed nickel-based superalloy in simulating aero gas turbine engine conditions. The results showed that the new superalloy is highly susceptible to high temperature oxidation. Within three of hours of oxidation, extensive oxide scales were formed. The formed oxide scales were analysed with electron dispersive spectroscopy (EDS) and morphology was studied with scanning electron microscope (SEM) for varied oxidation times. The oxidation products were determined with XRD and cross sections of all the oxidised superalloys were also studied. The elemental distribution of all the superalloys after oxidation was also studied with a view to understand and compare the characteristics of the new superalloy with other superalloys. Finally, an oxidation mechanism that is responsible for its faster degradation under elevated temperatures was established based on the results obtained with different techniques and presented in detail.
\end{abstract}

Keywords: Gas Turbine Engine Components, Superalloys, High Temperature Oxidation

\section{Introduction}

Newer materials with improved properties are essential in order to enhance the efficiency of gas turbine engines. Efforts made in this direction made it possible to develop a new superalloy for aero engines. The developed superalloy exhibits excellent high temperature strength properties [1]. For achieving enhanced efficiency, it is necessary that the developed superalloy should exhibit excellent high temperature oxidation resistance as it is detrimental at elevated temperatures. It reduces the superalloy component life by forming oxides at a faster rate, thereby reducing the load-carry capacity and potentially leading to catastrophic failure of components. Therefore, high temperature oxidation resistance of new superalloy is as important as its high temperature strength properties.

It is understood that the high temperature capability of superalloys depends on their chemistry such as nature of alloying elements and concentration of each alloying element. The major change is the addition of rhenium or of both ruthenium and iridium at the cost of chromium, which are named as the $3^{\text {rd }}$ or $4^{\text {th }}$ or $5^{\text {th }}$ generation superalloys respectively. Therefore, the chemistry of an advanced superalloy that belongs to $3^{\text {rd }}$ generation was greatly influenced by reducing chromium (Cr) content and increasing the rhenium (Re) content. Similarly, the $4^{\text {th }}$ and $5^{\text {th }}$ generation superalloys contain only about 3\% Cr but instead contain about 6\% Re, 1.5\% ruthenium (Ru) and/or iridium (Ir), which is a great contrast to the earlier generation superalloys containing about $10 \% \mathrm{Cr}$ and no $\mathrm{Re}, \mathrm{Ru}$ or Ir. These are unique elements, which can increase high temperature creep properties considerably, but make the superalloys susceptible to high temperature corrosion i.e. hot corrosion and high temperature oxidation. It is due to the fact that the new superalloys cannot form corrosion resistant alumina or chromia scale because of the presence of high rhenium content and small amounts of ruthenium and iridium. Their effect is similar to Mo on oxidation i.e. the high vapour pressure of its oxide. Therefore, the new alloying elements are harmful for high temperature corrosion resistance of advanced Ni-based superalloys.

Several failures of gas turbine engine blades were reported during service [2-7]. It was attributed primarily to high temperature corrosion of different types and established their relevant theories. Extensive amount of work was carried out in the laboratory on hot corrosion of several superalloys and established their degradation mechanisms [8-10]. It was shown that the hot corrosion of superalloys takes place through electrochemical reac- 
tions and it is an electrochemical phenomenon $[10,11]$. Further, high performance protective coatings were successfully identified for protection of superalloys under hot corrosion conditions [12-14]. Efforts made by other researchers in developing protecting coatings helped in understanding their behaviour [15-17]. Basically, the high temperature corrosion can be divided into oxidation and hot corrosion. The hot corrosion can be further divided into type I $\left(800^{\circ} \mathrm{C}-950^{\circ} \mathrm{C}\right)$ and type II $\left(600^{\circ} \mathrm{C}-750^{\circ} \mathrm{C}\right)$. As already mentioned above, any new superalloy material that is developed for gas turbine engine applications should exhibit excellent high temperature corrosion resistance apart from excellent mechanical properties.

In the present paper, high temperature oxidation characteristics of the newly developed superalloy is presented. XRD was used to determine the corrosion products that formed during high temperature corrosion processes. The surface morphologies were studied with scanning electron microscope (SEM) and the composition of oxidation products were analysed by EDS. Elemental distribution of the oxidised superalloys were determined with a view to establish its degradation mechanisms under oxidation conditions.

\section{Experimental}

The composition of newly developed advanced superalloy is presented in Table 1. In contrast to previous generation superalloys, the newly developed superalloy contains $6.5 \%$ rhenium and very small content of chromium, which makes it to exhibit very good high temperature strength properties [1]. Disc specimens of about $10 \mathrm{~mm}$ diameter and $2 \mathrm{~mm}$ thick were cut from the superalloy rods, polished them up to $600 \mathrm{SiC}$ surface finish, cleaned with tap water followed by distilled water and then decreased with acetone. Subsequently, the cyclic oxidation studies were carried out at $1100^{\circ} \mathrm{C} \pm 10^{\circ} \mathrm{C}$ for a period of 100 hours i.e. the specimens were placed in a furnace heated at $1100^{\circ} \mathrm{C}$ for 20 hours and allowed them to cool for 3 hours after removing from the furnace. Initially, the specimens were oxidized only for three hours to determine their weight change and subsequently for every 20 hours. The weight gain measurements were made each time after cooling to room temperature.

After completion of oxidation tests, the specimens were examined for their surface morphology with Scanning Electron Microscope (SEM) and the oxidation products were analyzed by Electron Dispersive Spectroscopy (ED S).

Table 1. The chemical composition of an advanced superalloy (wt\%).

\begin{tabular}{lcccccccc}
\hline Material & $\mathrm{Ni}$ & $\mathrm{Cr}$ & $\mathrm{Co}$ & $\mathrm{W}$ & $\mathrm{Al}$ & $\mathrm{Ta}$ & $\mathrm{Re}$ & $\mathrm{Hf}$ \\
\hline New alloy & $\mathrm{Bal}$ & 2.9 & 7.9 & 5.8 & 5.6 & 8.5 & 6.5 & 0.1 \\
\hline
\end{tabular}

Different phases formed during oxidation were analyzed by X-ray diffraction technique (XRD). Cross sections of oxidized speciemens were analyzed for understanding the effect of oxidation and then elemental distribution was determined in order to evolve the degradation mechanisms of advanced superalloy under high temperature oxidation conditions.

\section{Results and Discussion}

Figure 1 shows as oxidized advanced superalloy. As can be seen, the superalloy was oxidized to a maximum extent by forming thicker oxide scales and subsequently spalled. It indicates that the rate of formation of oxide scales is considerably high on the newly developed superalloy leading to the formation of thick oxide scales over a period of time and subsequently spalled because of adherence problem. In essence, the modified chemistry with increased addition of rhenium and tantalum and considerably reduced chromium made the new superalloy to oxidize at a faster rate when compared to earlier generation superalloys [18]. Typical surface morphology of the oxidized superalloy is shown in Figure 2. As can be seen, the surface morphology observed on the alloy is the spalled area as the oxide scale was spalled because of adherence problem due to its high thickness. Almost uniform morphology with reformed oxide scale in some regions is the characteristics of new superalloy. The EDS measurements revealed that the oxide scale was consisted the oxides of base as well as alloying elements. The cross section of oxidized new alloy shows that the oxidationaffected zone is very large (Figure 3). Faster oxidation and subsequent spallation is the reason for observing more affected region.

The XRD patterns along with their identifications for the oxidized superalloy after definite oxidation times are demonstrated in Figure $\mathbf{4}$ and the oxidation products were summarised in Table 2. The superalloy was formed

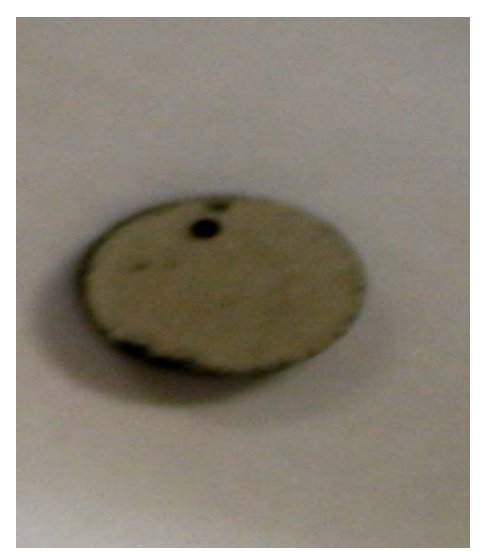

Figure 1. As oxidised advanced superalloy at $1100^{\circ} \mathrm{C}$ for 100 hours. 


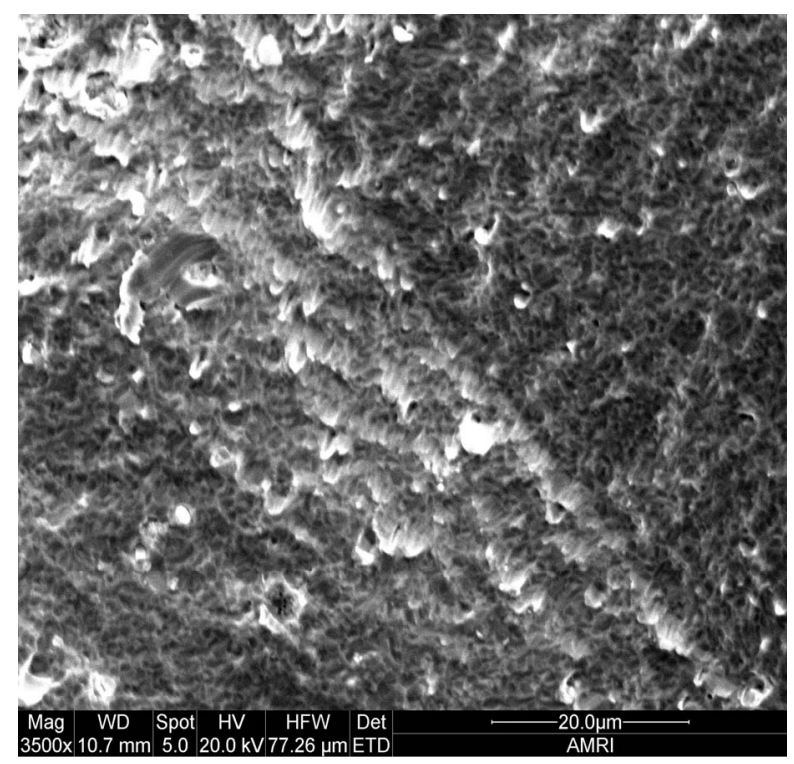

Figure 2. Surface morphology of oxidised superalloy at $1100^{\circ} \mathrm{C}$ for 100 hours.

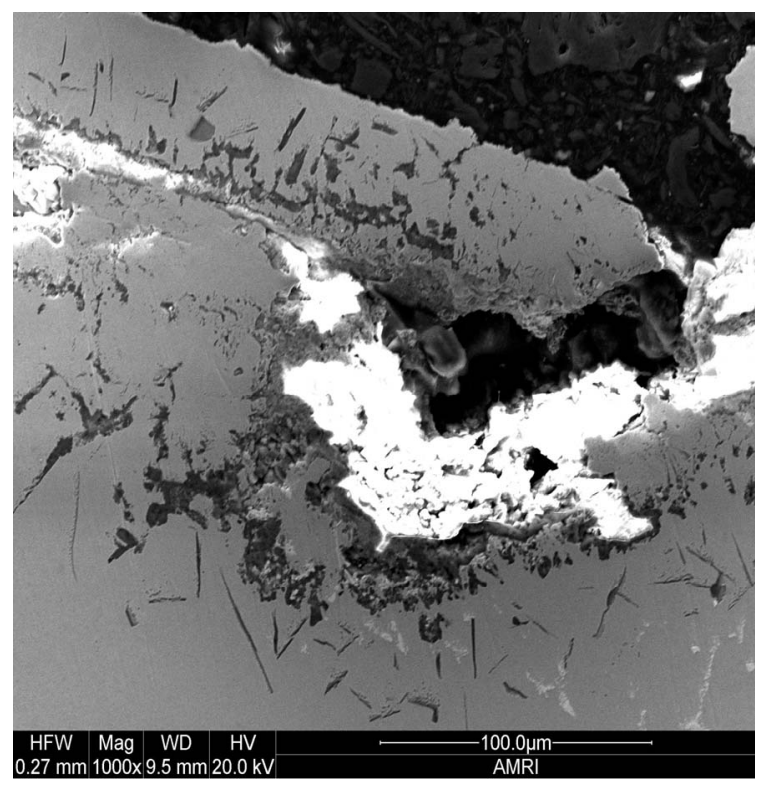

Figure 3. Cross section of oxidised superalloy at $1100^{\circ} \mathrm{C}$ for 100 hours.

Table 2. XRD data of oxidized superalloy.

\begin{tabular}{ll}
\hline Material & Oxidation products \\
\hline New superalloy & $\mathrm{NiO}, \mathrm{Co}_{3} \mathrm{O}_{4}, \mathrm{TaO}_{2}, \mathrm{WO}_{3}, \mathrm{Al}_{2} \mathrm{O}_{3}$ \\
\hline
\end{tabular}

nickel oxide as well as oxides of all the alloying elements (Table 2) during high temperature oxidation. The dominant oxidation product was nickel oxide with small peaks relating to oxides of cobalt, tantalum, tungsten and aluminium. It is due to the fact that the oxide scale was spalled because of high thickness.

The elemental distribution of an advanced superalloy after oxidation at $1100^{\circ} \mathrm{C}$ for 100 hours is illustrated in Figure 5. Discontinuous alumina in association with chromia is clearly observed on its surface. Rhenium and cobalt were present beneath the alumina and chromia scale. No nickel and cobalt oxides were present. These oxides might have spalled during cutting and polishing, as they are prominent in XRD. It demonstrates that the external scale was consisted of nickel and cobalt oxides, which were spalled after attaining maximum thickness and the internal scale was a mixture of alumina, chromia and tantalum oxide and hence observed in the cross section.

The present investigation clearly established that the newly developed superalloy is highly vulnerable to high temperature oxidation and degrades due to formation of a multilayer corrosion products consists of oxides of nickel as well as the alloying elements. During normal oxidation of superalloys, the oxides of most of the alloying elements as well as base are expected to form as given below:

$$
\begin{aligned}
& 2 \mathrm{Ni}+\mathrm{O}_{2}=2 \mathrm{NiO} \\
& 2 \mathrm{Cr}+3 / 2 \mathrm{O}_{2}=\mathrm{Cr}_{2} \mathrm{O}_{3} \\
& 3 \mathrm{Co}+2 \mathrm{O}_{2}=\mathrm{Co}_{3} \mathrm{O}_{4} \\
& 2 \mathrm{Al}+3 / 2 \mathrm{O}_{2}=\mathrm{Al}_{2} \mathrm{O}_{3} \\
& 2 \mathrm{~W}+3 \mathrm{O}_{2}=2 \mathrm{WO}_{3} \\
& 4 \mathrm{Ta}+5 \mathrm{O}_{2}=2 \mathrm{Ta}_{2} \mathrm{O}_{5} \\
& \mathrm{Ta}_{2} \mathrm{O}_{5}+\mathrm{Al}=\mathrm{Al}_{2} \mathrm{O}_{3}+\mathrm{TaO}_{2}+\mathrm{Ta} \\
& \mathrm{Ti}+\mathrm{O}_{2}=\mathrm{TiO}_{2} \\
& 4 \mathrm{Re}+7 \mathrm{O}_{2}=2 \mathrm{Re}_{2} \mathrm{O}_{7} \\
& \mathrm{Hf}+\mathrm{O}_{2}=\mathrm{HfO}_{2}
\end{aligned}
$$

Due to reaction with oxygen, rapid weight gain of the alloys takes place initially. After oxidation for an appropriate time, thermodynamically stable oxides such as $\mathrm{Al}_{2} \mathrm{O}_{3}, \mathrm{Cr}_{2} \mathrm{O}_{3}$ are formed as a dense oxide scale on the surface of superalloys. These oxide scales act as diffusion barriers for the ingress of deleterious species such as oxygen and sulphur. However, the oxidation is significantly high for the new superalloy, as it could not able to form a stable alumina or chromia scale because of change in its chemistry.

The following degradation mechanism has been proposed for the oxidation of new superalloy: diffusion processes occurring at elevated temperatures at the superalloy and environment interface act as a major degradation 


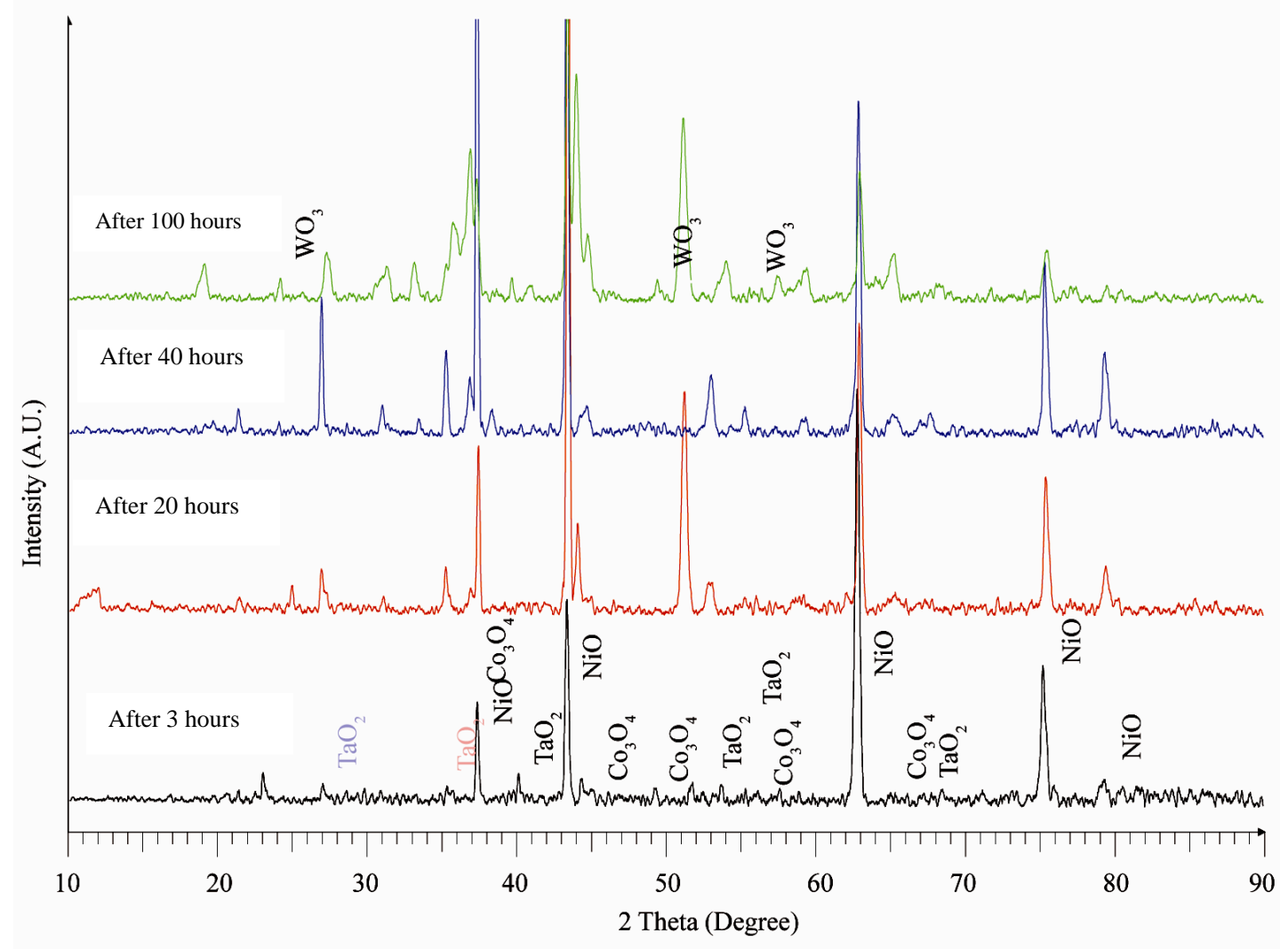

Figure 4. XRD Patterns of an advanced superalloy after oxidation at $1100^{\circ} \mathrm{C}$ for different times.
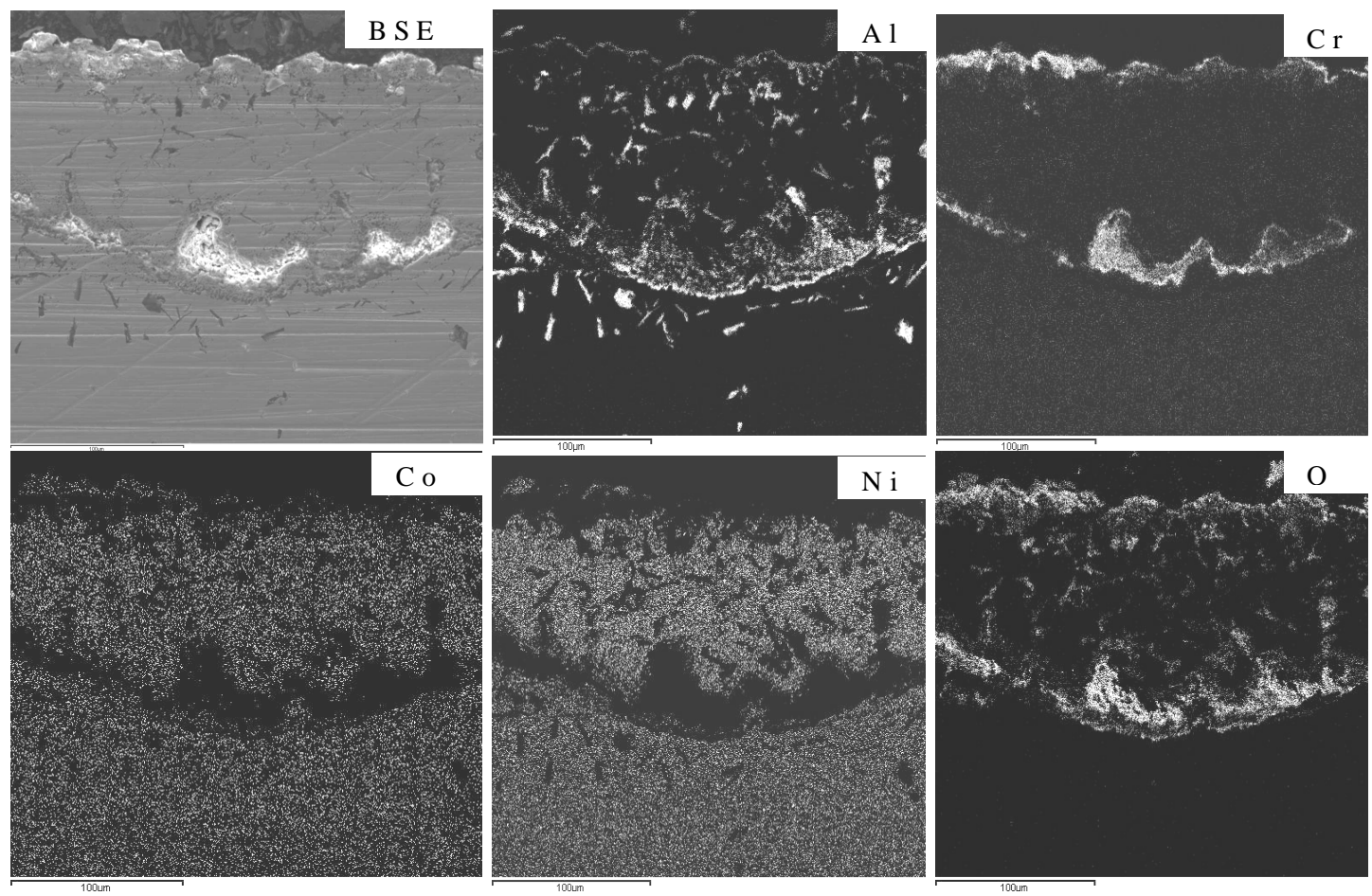

Figure 5. Elemental distribution of an advanced superalloy after oxidation at $1100^{\circ} \mathrm{C}$ for 100 hours. 
mode of the superalloy. At the superalloy interface, diffusion occurs primarily due to thermodynamic considerations at the elevated temperatures. The new superalloy contains a number of alloying elements like Co, Ta, W, $\mathrm{Re}, \mathrm{Al}, \mathrm{Cr}$ etc. mainly to enhance high temperature mechanical characteristics. The nickel and alloying elements of the superalloy diffuse outwards leading to the formation of phases that contain non-protective elements during high temperature oxidation process. As a result, nonprotective oxide scales form rather than continuous and protective pure alumina scale. It is important to mention that nickel appears to have high affinity towards oxygen at elevated temperatures and hence diffuses outwards at a faster rate, interact with oxygen ions to form nickel oxide. This process leads to extensive nickel oxide growth and forms thicker scales. Thicker scales lead to spall after reaching to certain thickness due to adherence problem. Further, excessive growth of nickel oxide scale, in association with alloying elements of superalloy like cobalt, tantalum, tungsten and rhenium, leads to the formation of non-protective oxide scales with large volumes. Consequently, spallation of oxide scale takes place because of non-adherence to the superalloys. Practical observation of extensive oxide scale growth (Figure 5) and subsequent spallation clearly supports the proposed degradation mechanism. A schematic representation of degradation of new superalloy during high temperature oxidation is presented in Figure 6.

New

Super-alloy

(a)

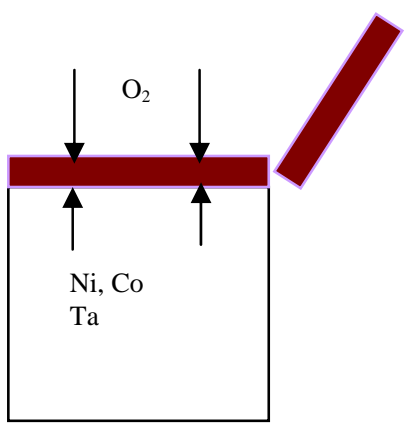

(c)

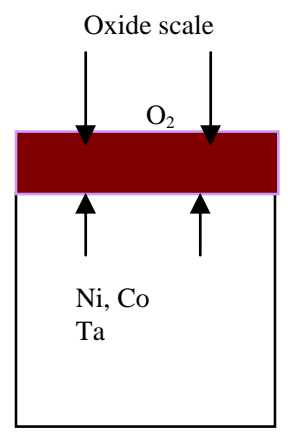

(b)

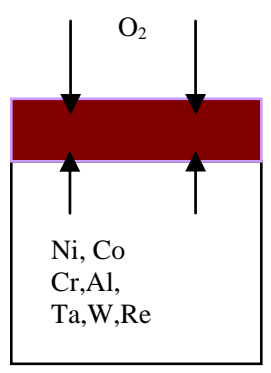

(d)

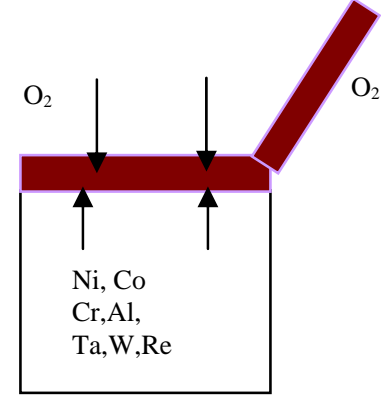

(e)

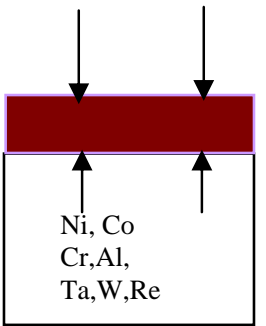

(f)
Figure 6. Sequence of degradation processes for an advanced superalloy during high temperature oxidation process. (a) Before oxidation; (b) During 3 hours of oxidation; (c) After 3 hours of oxidation; (d) During 20 hours of oxidation; (e) After 20 hours of oxidation; (f) After 40, 60, 80, 100 hours of oxidation and continuation of process leading to failure of the alloy.

\section{Development of Smart Coatings}

The present results clearly stresses the need to apply high performance protective coatings for its protection against high temperature oxidation as the gas turbine engines encounter oxidation problem during service. The protective coatings allow the gas turbine engines to operate at varied temperatures and enhance their efficiency by eliminating failures during service. Research in this direction has resulted in design and development of smart coatings which provide effective protection to the superalloy blades for the designed period against type I, type II hot corrosion and high temperature oxidation that are normally encountered in gas turbine engines which in turn enhances the efficiency of gas turbine engines considerably $[18,19]$. This is a major developmental work in the area of gas turbine engines used in aero, marine and industrial applications. Unlike the conventional/existing coatings, the smart coatings provide total protection to the superalloy components used in aero, marine and industrial applications by forming appropriate protective scales depending on the surrounding environmental conditions [18, 19].

\section{REFERENCES}

[1] N. Das, US patent 5,925,198, July 1999

[2] M. R. Khajavi and M. H. Shariat, "Failure of First Stage Gas Turbine Blades,” Engineering Failure Analysis, Vol. 11, No. 4, 2004, pp. 589-597. doi:10.1016/j.engfailanal.2003.08.010

[3] J. M. Gallardo, J. A. Rodrigue and E. J. Herrera, "Failure of Gas Turbine Blades,” Wear, Vol. 252, No. 3-4, 2002, pp. 264-268. doi:10.1016/S0043-1648(01)00885-7

[4] N. Eliaz, G. Shemesh and R. M. Latarision, "Hot Corrosion in Gas Turbine Components," Engineering Failure 
Analysis, Vol. 9, No. 1, 2002, pp. 31-43. doi:10.1016/S1350-6307(00)00035-2

[5] T. J. Carter, "Common Failures in Gas Turbine Blades," Engineering Failure Analysis, Vol. 12, No. 2, 2005, pp. 237-247. doi:10.1016/j.engfailanal.2004.07.004

[6] R. Nutzel, E. Affeldt and M. Goken, "Damage Evolution during Thermo-Mechanical Fatigue of a Coated Monocrystalline Nickel-Bas Superalloy,” International Journal of Fatigue, Vol. 30, No. 2, 2008, pp. 313-317. doi:10.1016/j.ijfatigue.2007.01.045

[7] R. S. J. Corran and S. J. Williams, "Lifing Methods and Safety Criteria in Aero Gas Turbines," Engineering Failure Analysis, Vol. 14, No. 3, 2007, pp. 518-526. doi:10.1016/j.engfailanal.2005.08.010

[8] I. Gurrappa, "Hot Corrosion Behaviour of CM 247 LC Alloy in $\mathrm{Na}_{2} \mathrm{SO}_{4}$ and $\mathrm{NaCl}$ Environments," Oxidation of Metals, Vol. 51, No. 5-6, 1999, pp. 353-382. doi:10.1023/A:1018831025272

[9] I. Gurrappa, "Hot Corrosion Behaviour of Nimonic-75," Journal of High Temperature Materials Science, Vol. 38, 1997, pp. 1-9

[10] I. Gurrappa, "Influence of Alloying Elements on Hot Corrosion of Superalloys and Coatings-Necessity of Smart Coatings," Materials Science and Technology, Vol. 19, 2003, pp. 178-183

[11] I. Gurrappa, "Overlay Coating Degradation an Electrochemical Approach,” Journal of Materials Science Letters, Vol. 18, No. 21, 1999, pp. 1713-1717. doi:10.1023/A:1006694220055
[12] I. Gurrappa, "Identification of Hot Corrosion Resistant MCrAlY Based Bond Coatings for Gas Turbine Engine Applications," Surface and Coating Technology, Vol. 139, No. 2-3, 2001, pp. 272-283. doi:10.1016/S0257-8972(00)01156-7

[13] I. Gurrappa, "Hot Corrosion Behaviour of Protectuve Coatings on CM 247 LC Superalloy,” Materials and Manufacturing Processes, Vol. 15, 2000, pp. 761-767

[14] I. Gurrappa and A. Sambasiva Rao, "Thermal Barrier Coatings for Enhanced Efficiency of Gas Turbine Engines," Surface and Coating Technology, Vol. 201, 2006, pp. 30163029

[15] R. Mevrel, "State of the Art on High Temperature Corrosion Resistant Coatings,” Materials Science and Engineering A, Vol. 120-121, 1989, pp. 13-24

[16] R. Mobarra, A. H. Jaffari and M. Karamirezhaad, "Hot Corrosion Behaviour of MCrAlY Coatings on IN 738LC," Surface and Coating Technology, Vol. 201, 2006, pp. 22022207

[17] M. M. Warres, "Improved Aluminide McrAlX Coating Systems for Superalloys using CVD low activity Aluminizing," Surface and Coating Technology, Vol. 163164, 2003, pp. 106-111

[18] I. Gurrappa, "Final Report on 'Design and Development of Smart Coatings for Aerospace Applications’ Submitted to European Commission,” July 2008

[19] I. Gurrappa, "Identification of a Smart Bond Coating for Gas Turbine Engine Applications,” Coating Technology Research, Vol. 5, 2008, pp. 385-390 